\title{
Use of Advance Care Planning Billing Codes in a Tertiary Care Center Setting
}

\author{
Peter Kim, BS, MPH, Jeanette M. Daly, RN, PhD, Maresi Berry-Stoelzle, MD, PhD, \\ Megan Schmidt, MPH, and Barcey T. Levy, PhD, MD
}

Introduction: The Centers for Medicare and Medicaid Services released the final payment rules for reimbursement of advance care planning (ACP) effective January 2016. In its first year, 23,000 providers nationwide submitted 624,000 claims using the Current Procedural Terminology codes 99497 and 99498. The objectives of our study were to 1) assess the frequency of ACP codes used at a single academic tertiary care center in Iowa, 2) determine when and by whom the codes were used, and 3) summarize ACP clinical notes.

Methods: Using the electronic medical record data warehouse from a single tertiary teaching hospital and affiliated clinics, date of service, department where service was provided, provider name and type, patient medical record number, date of birth, and gender linked to the ACP codes 99497 and 99498 were collected. The content of ACP clinical notes were reviewed and summarized. Study period was from January 1, 2016 through September 19, 2018.

Results: During the 33 months, code 99497 was used 17 times and code 99498 was never used. Code 99497 was successfully reimbursed 4 times.

Discussion: Charges were not reimbursed if the ACP visits did not meet the minimum time requirement or were conducted by an individual not considered a qualified health care professional per Medicare rules.

Conclusion: ACP codes 99497 and 99498 were very rarely used at this tertiary care center during the initial 33-months after the Medicare rules went into effect. Interventions are needed to promote the use of ACP codes, so the time spent in important ACP discussions are properly compensated. (J Am Board Fam Med 2019;32:827-834.)

Keywords: Advance Care Planning, Current Procedural Terminology, Data Warehousing, Electronic Health Records, Health Policy, Incentive Reimbursement, Iowa, Medicaid, Medicare, Palliative Care, Teaching Hospitals, Tertiary Care Centers

Conversations about patient values and preferences for care are most effective if they occur before end-of-life decisions need to be made. ${ }^{1}$ The goal of advance care planning (ACP) is to help patients

This article was externally peer reviewed.

Submitted 2 April 2019; revised 9 July 2019; accepted 9 July 2019.

From the Department of Family Medicine, University of Iowa Carver College of Medicine, Iowa City, IA (PK, JMD, MBS, MS, BTL); Department of Epidemiology, University of Iowa, College of Public Health, Iowa City, IA (BTL).

Funding: PK was supported by the Department of Family

Medicine, University of Iowa Carver College of Medicine.

Conflict of interest: none declared.

Corresponding author: Peter Kim, BS, MPH, University of Iowa, Carver College of Medicine, Department of Family Medicine, 01105-C PFP, 200 Hawkins Drive, Iowa City, IA, 52242 (E-mail: peter-kim@uiowa.edu). make decisions so that they receive care that is aligned with their goals and values. ${ }^{2,3}$ Components of the ACP conversation include goals, prognosis, treatment plan, functional abilities, psychosocial measures, and quality of life. ${ }^{2,4}$ Key elements of ACP documentation include history of present illness, values and preferences of the patient, identification of a medical decision maker, orders for life-sustaining treatment, and duration of the ACP conversation. ${ }^{5}$ Depending on the visit purpose and time allotted, not all topics may get addressed within the time allowed.

Constraints of time, lack of a payment mechanism, and insufficient training for ACP conversations have been noted as barriers for providers to have end-of-life discussions. ${ }^{6-8}$ In response, the 
Centers for Medicare and Medicaid Services (CMS) released the final payment rules on October 30, 2015 for Medicare reimbursement of physicians who consult with their patients for ACP. Effective January 1, 2016, Medicare paid $\$ 86$ for 30 minutes of ACP in a physician's office and $\$ 80$ for the same service in a hospital using the Current Procedural Terminology (CPT) billing code 99497. ${ }^{7,9}$ In both settings, Medicare also paid up to $\$ 75$ for 30 additional minutes of consultation using the add-on CPT code $99498 .^{10}$ Providers can submit the codes during a routine office visit, a Medicare annual wellness visit, or when there is a change in health care status. ${ }^{11}$

The ACP codes are time based and are usually charged by physicians or other health care professionals who are under the supervision of the patient's treating physician. Code 99497 can be charged for the explanation or discussion of advance directives using standard forms by the physician or other qualified health care professional. This code is utilized for the first 30 minutes of the discussion, and $50 \%$ of those 30 minutes must be face to face with the patient, family member(s), and/or surrogate. Code 99498 is for each additional 30 minutes. Codes 99497 and 99498 are charged separately if submitted together, and can also be charged in addition to a code for any other procedure.

Use of ACP codes at a Midwestern tertiary care center in the United States was unknown. The purposes of this study were to: 1) assess use of codes 99497 and 99498, 2) determine when and by whom the codes were used, and 3) summarize key points of ACP clinical notes.

\section{Methods}

The study and methods were approved by the University of Iowa Institutional Review Board. A retrospective chart review in the electronic medical record (EMR), Epic (Verona, WI), was conducted. ACP codes 99497 and 99498 were pulled from Epic's enterprise Data Warehouse that contained data from January 1, 2016 through September 19, 2018 for the hospital and all associated clinics within the health system. Output included ACP codes charged, date of service, department where service was provided, provider name, provider type, medical record number, patient date of birth, and patient gender. Reimbursements for the charged ACP codes were confirmed by the Office of Patient Financial Services.
Two reviewers (JD and PK) performed a review of the clinical notes where codes 99497 or 99498 were charged. After development of a preliminary code list, initial content analysis was conducted by one investigator (JD) to identify general themes of ACP documentation and abstracted data that fell under each theme. A second reviewer (PK) independently repeated the same step. Afterward, the two compared their work together to organize the themes, and agreed on the presented results.

\section{Results}

From the Epic data pull of September 19, 2018 covering the time period of January 1, 2016 to September 19, 2018, code 99497 was charged by providers for 17 unique patients. Table 1 summarizes patient demographics and summary of clinical notes when ACP codes were used. The initial date where an ACP code was used was May 31, 2017, which is nearly 17 months after CMS began allowing this code. Code 99498 was not used during the entire timeframe. Internal Medicine and Family Medicine were the only two specialties that utilized the ACP codes. Thirteen patients were seen in the Palliative Care clinic in Internal Medicine Specialty Clinics (\#1 to 3,5 to 14$), 1$ in the Internal Medicine Gastroenterology Clinic (\#4), and 3 in the Family Medicine clinics (\#15 to 17). Age of patients ranged from 35 to 87 years with a mean of 64 years. The codes were never used for a pediatric patient even though it can be applied to any patient regardless of age. Ten (59\%) subjects were male. Four (24\%) patients were deceased at the time of the data pull.

Heart disease was the main reason 11 patients had an ACP discussion. Other reasons included chronic kidney disease, chronic obstructive pulmonary disease, metastatic melanoma, metastatic pancreatic cancer, and oropharyngeal carcinoma. Ten (59\%) of the patients had goals of care documented. Various patient goals discussed included the following: to live longer, maintain independent functional status, and spend time with wife/family at home; to continue aggressive care measures in alignment with further surgical measures; and to maintain/improve function, find comfort and relief of symptoms, maintain family relationships, and complete life goals. The content of ACP clinic notes documented in the EMR included discussion of code status, living will, durable power of attor- 
Table 1. Patient Demographics and Summary of Advance Care Planning Clinical Notes $(\mathrm{n}=17)$

\begin{tabular}{|c|c|c|c|c|c|c|c|c|c|}
\hline ID & $\begin{array}{l}\text { Age } \\
\text { (years) }\end{array}$ & $\begin{array}{l}\text { Provider } \\
\text { Type }\end{array}$ & Specialty & Primary Diagnoses & $\begin{array}{l}\text { Code Status } \\
\text { Documented }\end{array}$ & $\begin{array}{l}\text { Living } \\
\text { Will }\end{array}$ & DPOA & IPOST & $\begin{array}{c}\text { Hospice } \\
\text { Status }\end{array}$ \\
\hline 1 & 69 & ARNP & $\mathrm{IM} / \mathrm{PC}$ & $\begin{array}{l}\text { HF, COPD, Afib, } \\
\text { CKD, MI }\end{array}$ & Yes & Yes & Yes & Yes & Yes \\
\hline 2 & 87 & MD & $\mathrm{IM} / \mathrm{PC}$ & Afib, CAD, CKD & Yes & Yes & Yes & Yes & Yes \\
\hline 3 & 59 & ARNP & $\mathrm{IM} / \mathrm{PC}$ & Cholangiocarcinoma & Yes & No & Yes & Yes & Yes \\
\hline 4 & 80 & MD & IM/GI & $\begin{array}{l}\text { CAD, CVD, } \\
\text { perihepatic fistula }\end{array}$ & No & No & No & No & No \\
\hline 5 & 49 & MD & $\mathrm{IM} / \mathrm{PC}$ & Renal failure & No & No & Yes & No & No \\
\hline 6 & 55 & MD & $\mathrm{IM} / \mathrm{PC}$ & COPD & Yes & No & Yes & No & No \\
\hline 7 & 70 & MD & $\mathrm{IM} / \mathrm{PC}$ & Lingual cancer & No & No & Yes & No & No \\
\hline 8 & 70 & MD & $\mathrm{IM} / \mathrm{PC}$ & HF, CVA, DM1 & Yes & No & Yes & No & No \\
\hline 9 & 63 & MD & $\mathrm{IM} / \mathrm{PC}$ & $\mathrm{HF}$ & Yes & Yes & Yes & No & No \\
\hline 10 & 52 & MD & $\mathrm{IM} / \mathrm{PC}$ & $\mathrm{HF}$ & No & No & Yes & No & No \\
\hline 11 & 58 & DO & $\mathrm{IM} / \mathrm{PC}$ & $\mathrm{HF}, \mathrm{CKD}, \mathrm{DM} 2$ & Yes & No & Yes & No & Yes \\
\hline 12 & 75 & ARNP & $\mathrm{IM} / \mathrm{PC}$ & $\mathrm{HF}$ & Yes & No & Yes & No & No \\
\hline 13 & 63 & ARNP & $\mathrm{IM} / \mathrm{PC}$ & $\mathrm{HF}$ & Yes & No & Yes & No & No \\
\hline 14 & 35 & ARNP & $\mathrm{IM} / \mathrm{PC}$ & $\begin{array}{l}\text { Melanoma with } \\
\text { brain metastasis }\end{array}$ & No & No & Yes & No & No \\
\hline 15 & 67 & $\mathrm{PA}$ & FM & HTN, obesity & No & Yes & No & No & No \\
\hline 16 & 58 & MD & FM & HF, Afib, obesity & No & Yes & No & No & No \\
\hline 17 & 84 & MD & FM & CHF, CKD, HTN & No & Yes & No & No & No \\
\hline
\end{tabular}

Afib, atrial fibrillation; ARNP, advanced registered nurse practitioner; CAD, coronary artery disease; CVA, cerebral vascular accident; $\mathrm{CHF}$, congestive heart failure; CKD, chronic kidney disease; COPD, chronic obstructive pulmonary disease; CVD, cerebrovascular disease; DM1/2, diabetes type 1/2; DO, Doctor of Osteopathic Medicine; DPOA, durable power of attorney for health care; FM, Family Medicine; HF, heart failure; HTN, hypertension; IM/GI, Internal Medicine/Gastroenterology; IM/PC, Internal Medicine/ Palliative Care; IPOST, Iowa Physicians Orders for Scope of Treatment (legally binding document); MD, Doctor of Medicine; MI, myocardial ischemia or infarct; PA, Physician Assistant.

ney (DPOA) for health care, the Iowa Physicians Orders for Scope of Treatment (IPOST), medical decision making and hospice. For all cases, the DPOA for health care was discussed the most (Table 1). For each of the clinic notes referenced above, a dot phrase template was used to document the time spent in ACP. An example of an ACP dot phrase, adapted from the Serious Illness Conversation Guide developed by Ariadne Labs (Boston, MA), was developed by the authors to not only guide ACP conversations, but also to help clinicians document important components for successful reimbursement (Table 2). ${ }^{12}$

Table 3 shows the summary of reimbursement of CPT code 99497. Code 99497 was reimbursed for 4 of the 17 patients. Four cases (\#1 to 4) were reimbursed because it was conducted by a qualified health care provider and met the required face-toface time per Medicare rules. Ten encounters in the Palliative Care clinic (\#5 to 14) were marked by the provider as 99497 but were not reimbursed, primarily because the ACP visit was conducted by a registered nurse $(\mathrm{RN})$.
Following are the description and documentation examples for the 4 cases where code 99497 was successfully reimbursed.

\section{Patient 1}

Ms. $\mathrm{U}$ is a 69 -year-old woman with combined systolic and diastolic heart failure due to ischemic cardiomyopathy and coronary artery disease. She has a history of coronary artery bypass graft, and a recent stent placement with lesions not amenable to revascularization. She also suffers from chronic obstructive pulmonary disease and is on home oxygen. She had 7 hospitalizations in the last year due to recurring chest pain. After her most recent hospital admission, she followed up in the outpatient Palliative Care clinic. The visit was conducted by an advanced registered nurse practitioner (ARNP) and they spent a total of 30 minutes discussing decisions regarding code status and hospice outside of the 25 minutes of medical evaluation and management of the patient's dyspnea and anxiety. The patient wishes her code status to be Do Not Resuscitate (DNR), after talking to her daughter since 
Table 2. An Example of Epic Advance Care Planning Checklist SmartPhrase, Adapted from the Serious Illness Care Conversation by Ariadne Labs ${ }^{12}$

Serious Illness Care Plan (.famacp)

1. Set up the conversation

*Introduce purpose

*Prepare for future decisions

*Ask permission

2. Assess understanding and preferences

3. Share concerns about the future

*Frame as a "wish ... worry",

"hope ... worry" statement

*Allow silence, explore emotion
"I'd like to talk about what is ahead with your illness and do some thinking in advance about what is important to you so that I can make sure we provide you with the care you want - is this okay?" (The patient must give permission for this discussion, per Medicare guidelines. They can decline to discuss.)

"What is your understanding now of where you are with your illness?"

"How much information about what is likely to be ahead with your illness would you like from me?"

"I want to share with you my understanding of where things are with your illness ..."

Uncertain: "It can be difficult to predict what will happen with your illness. I hope you will continue to live well for a long time but I'm worried that you could get sick quickly, and I think it is important to prepare for that possibility."

OR

Function: "I hope that this is not the case, but I'm worried that this may be as strong as you will feel, and things are likely to get more difficult."

OR

Time: "I wish we were not in this situation, but I am worried that time may be as short as year)." (express as a range, e.g., days to weeks, weeks to months, months to a

"What are your most important goals if your health situation worsens?"

"What are you biggest fears and worries about the future with your health?"

"What gives you strength as you think about the future with your illness?"

"What abilities are so critical to your life that you can't imagine living without them?"

"If you become sicker, how much are you willing to go through for the possibility of gaining more time?"

"How much does your family know about your priorities and wishes?"

"Do you want to make it more concrete?" Consider IPOST.

"I've heard you say that ___ is really important to you. Keeping that in mind, and what we know about your illness, I recommend that we __. This will help us make sure that your treatment plans reflect what's important to you."

"How does this plan seem to you?"

"I will do everything I can to help you through this."

${ }^{*}$ Check in with patient

*Affirm commitment

6. Document your conversation

7. Communicate with key clinicians

IPOST, Iowa Physicians Orders for Scope of Treatment.

Statement of Patient Consent and Time Spent on Advance Care Planning: [Patient name] voluntarily consented to an advance care planning discussion to aid in considering and prioritizing their treatment goals. I spent ${ }^{* *}$ minutes face-to-face with [patient's name] and [add any other participants (family, RN, MA, etc.) discussing Advance Care Planning.

her last admission, and thinks she may now be interested in hospice support, although she previously was not. The ARNP submitted for reimbursement for both a 99214, a code for an office visit with moderate complexity medical decision making, ${ }^{13}$ and 99497 , and documented in the clinic note as follows:

"Time Spent: I spent a total of 25 minutes as part of evaluation and management; over 50\% spent in counseling and coordination of care about symptom manage- ment strategies. In addition, the patient verbally consented to an advance care planning discussion to aid in considering and prioritizing their treatment goals. I spent 30 minutes with the patient as part of this advance care planning discussion separate from evaluation and management."

\section{Patient 2}

Mr. V is an 87-year-old man with end-stage pulmonary fibrosis, coronary artery disease, atrial fi- 
Table 3. Summary of Reimbursement for CPT Code 99497 for 17 Patients

\begin{tabular}{|c|c|c|c|c|c|}
\hline ID & $\begin{array}{l}\text { Qualified Provider } \\
\text { ACP Time } \\
\text { (minutes) Spent }\end{array}$ & $\begin{array}{l}\text { RN ACP Time } \\
\text { (minutes) Spent }\end{array}$ & $\begin{array}{l}\text { CPT } 99497 \text { Billed and } \\
\text { Reimbursed }\end{array}$ & $\begin{array}{c}\text { Actual Reimbursed } \\
\text { Dollars }\end{array}$ & Payers*† \\
\hline 1 & 30 & 0 & Yes & $\$ 61.97$ & Medicare \& Supplement \\
\hline 2 & 30 & 0 & Yes & $\$ 72.90$ & Medicare \& Supplement \\
\hline 3 & 30 & 0 & Yes & $\$ 61.97$ & Medicare \& Supplement \\
\hline 4 & 30 & 0 & Yes & $\$ 76.42$ & Medicare Replacement \\
\hline 5 & 0 & 16 & No & $\$ 0.00$ & Private \\
\hline 6 & 0 & 20 & No & $\$ 0.00$ & Medicare Replacement \\
\hline 7 & 0 & 25 & No & $\$ 0.00$ & Medicare \& Supplement \\
\hline 8 & 0 & 25 & No & $\$ 0.00$ & Medicare \& Supplement \\
\hline 9 & 0 & 25 & No & $\$ 0.00$ & Medicaid \\
\hline 10 & 0 & 25 & No & $\$ 0.00$ & Private \\
\hline 11 & 0 & 20 & No & $\$ 0.00$ & Medicare \\
\hline 12 & 0 & 20 & No & $\$ 0.00$ & Medicare \\
\hline 13 & 0 & 20 & No & $\$ 0.00$ & Medicare \& Supplement \\
\hline 14 & 0 & 16 & No & $\$ 0.00$ & Medicare \& Supplement \\
\hline 15 & 5 & 0 & No & $\$ 0.00$ & Medicare \& Supplement \\
\hline 16 & 8 & 0 & No & $\$ 0.00$ & Medicare \\
\hline 17 & 25 & 0 & No & $\$ 0.00$ & Medicare \\
\hline
\end{tabular}

ACP, advance care planning; CPT, current procedural terminology, RN, registered nurse.

${ }^{*}$ Medicare \& Supplement: Medicare is primary insurance; secondary commercial insurance or Medicaid were supplemental to the Medicare coverage and may have paid a portion of the total payment amount that is billed.

${ }^{\dagger}$ Medicare Replacement: also known as Medicare Part C; a plan offered by private health insurance companies that provide the same coverage as Medicare Part A and Part B, and may include other benefits not normally covered by standard Medicare (e.g., prescription, dental).

brillation with pacemaker and defibrillator, and chronic kidney disease. He was recently admitted to the Cardiovascular Intensive Care Unit because of infection of his biventricular pacemaker, which had to be extracted and replaced. He was referred for outpatient palliative care. His wife accompanied him to the visit. A palliative care physician conducted the visit and they spent 30 minutes discussing his recent hospitalization, code status, values, and concerns. He recounted his long history of pulmonary disease and explained that he is depressed and anxious about his loss of strength and his inability to do the things in life that he enjoys. When discussing the value of IPOST, his wife asked if the document could be completed at another appointment, saying "it has been a long day and I can see that my husband is becoming very fatigued." They agreed to meet again early next week to complete the IPOST, have a conversation about hospice, and discuss his symptoms and recommendations for physical therapy. The physician billed for both 99214 and 99497 and documented in the clinic note as follows:
"Time Spent: I spent a total of 35 minutes as part of evaluation and management. In addition, the patient verbally consented to an advance care planning discussion to aid in considering and prioritizing their treatment goals. I spent 30 minutes with the patient as part of this advance care planning discussion separate from evaluation and management."

\section{Patient 3}

Ms. W is a 59 -year-old female with a history of myotonic muscular dystrophy and a new diagnosis of cholangiocarcinoma. She did not want chemotherapy unless it has a realistic chance of prolonging her life for many months or years and was focusing on quality of life and comfort. She was seen by the outpatient palliative care service for a routine followup to discuss symptom management, hospice, goals of care, and completion of IPOST and DPOA. This visit was conducted by an ARNP. DPOA was completed at this visit and notarized. IPOST was discussed and completed as well. Patient is chronically fatigued from her muscular dystrophy. She wishes to have a natural death, and 
does not want further hospitalizations. Her focus is on comfort, and she is not interested in artificial nutrition. The ARNP coded the visit as a 99215, a code for an office visit with a comprehensive level of documentation, ${ }^{14}$ and 99497 , and documented as follows:

"Time Spent: I spent a total of 45 minutes as part of evaluation and management. In addition, the patient verbally consented to an advance care planning discussion to aid in considering and prioritizing their treatment goals. I spent 30 minutes with the patient as part of this advance care planning discussion separate from evaluation and management."

\section{Patient 4}

Mr. $\mathrm{X}$ is an 80 -year-old male with an abdominal aortic aneurysm, cerebrovascular disease, coronary artery disease status post coronary angioplasty and multiple stent placements, and prostate cancer status post prostatectomy, and cholecystectomy. $\mathrm{He}$ was referred to the Gastroenterology/Hepatology clinic for his recurrent perihepatic fluid collection. He feels generally well except for his chronic fatigue. The hepatology specialist reviewed Mr. X's previous images and finds that there may be a communication between the fluid collection and the bile duct and plans to obtain a cholescintigraphy. The physician submits 99205 , a code for an office visit with a comprehensive history, examination and high medical decision making, ${ }^{15}$ and 99497, and documented in the clinic note as follows:

"I spent 60 minutes face-to-face with the patient, of which 30 minutes consisted of counseling and/or coordination or care."

The physician also documented: "I spent 35 minutes in nonface-to-face prolonged care time last week, in preparation for the upcoming patient's clinic visit. Time was spent reviewing records extensively from EPIC (media) including past clinic notes, progress notes, prior inpatient notes, labs results, radiologic findings, procedure notes and medication lists."

In 2 of the 3 cases seen in the Department of Family Medicine, 99497 was charged but was not billed, likely because the time spent for ACP was documented as less than $50 \%$ of face-to-face time of 30 minutes. In the third case, greater than $50 \%$ of face-to-face time of a Medicare Wellness visit was spent with proper documentation and 99497 was charged by a family physician, but was not reimbursed. On further inquiry, it was found that codes 99497 and 99498 had not yet been added to the Department of Family Medicine Fee Schedule on Epic, making it so billers were not aware that Family Medicine could be appropriately reimbursed for these codes.

The following are the description and documentation examples of the 2 cases from the Family Medicine Clinic where a provider attempted to charge 99497, but were not reimbursed due to not meeting the "greater than $50 \%$ rule" of the 30 minutes of face-to-face time. ${ }^{9,16}$

\section{Patient 15}

Ms. $\mathrm{Y}$ is a 67 -year-old female with hypertension and morbid obesity who presented for a Medicare Annual Wellness visit. Before the visit, the patient responded that she has not completed paperwork detailing her wishes at the end of her life, and also answered "no" when asked if she was interested in receiving information on how to make sure that her wishes are honored if she were to become ill. The certified physician assistant (PA) revisits the patient's answers during the patient encounter and the patient confirms that she is not interested in the discussion. The PA documented as follows under the additional services provided during the Medicare Annual Wellness Visit:

"Advance Care Planning/Counseling for Living Will: Patient voluntarily consented to and received counseling for advance care planning/counseling for living will for 5 minutes. Information regarding $D P O A$ for health care, code status, and artificial feeding was provided. Pertinent documents if signed are scanned into the electronic medical record. Patient is not interested in addressing this issue any further."

\section{Patient 16}

Ms. $\mathrm{Z}$ is a 58 -year-old female with right heart failure due to pulmonary hypertension, chronic atrial fibrillation, and obesity hypoventilation syndrome who presented for a Medicare Annual Wellness visit. Before the visit, she answered "yes" to wishing to complete an advance directive or living will. The physician noticed the patient's answer and reviewed the patient's living will with the patient during the encounter, and documented as follows under additional service provided for the Medicare Annual Wellness Visit:

"Advance Care Planning/Counseling for Living Will: Patient voluntarily consented to and received counseling for advance care planning/counseling for liv- 
ing will for 8 minutes. Information regarding DPOA for health care, code status, and artificial feeding was provided. Pertinent documents if signed are scanned into the electronic medical record - (16 to 45 minutes total) - scanned under Living Will (2015): wishing [wishes] and phone numbers reviewed and are up to date for daughters and husband."

\section{Discussion}

Several articles have been published on how to appropriately document and then bill for ACP., 5,9 No studies, however, have assessed use of ACP codes in a large, tertiary care center or their reimbursement for ACP. Since Medicare coverage for ACP was initiated in 2016, code 99497 had rarely been used and 99498 was never used at this Midwestern tertiary care center. Possible reasons for disuse of ACP codes may be that providers are unaware of the relatively new ACP codes. While the American Medical Association estimated that 300,000 patients would be billed using ACP codes in the first year when ACP codes 99497 and 99498 are introduced, there were 624,246 charges submitted by 22,864 providers for ACP services in 574,621 Medicare beneficiaries nationwide between January 1 and December 31, 2016 (total submitted charge amount: \$93,025,538; total Medicare payment amount: $\$ 43,357,881) .{ }^{6,17,18}$ In 2016, there were 55 million people with Medicare, indicating that ACP codes have been used in approximately $1 \%$ of the Medicare population in 2016. ${ }^{6}$ In the 6 New England states, similar findings occurred. Fewer than $1 \%$ of Medicare beneficiaries had Part A and B claims filed for ACP in 2016. ${ }^{19}$ However, across the United States in the first 3 quarters of 2017, use of ACP CPT codes increased to $2.2 \%$ for Medicare Part B claims. ${ }^{20}$ The number of claims submitted for ACP services in theory should continue to increase as the Medicare population increased to 60 million in 2018 . For reimbursement of the ACP codes to become congruent with the occurrence of ACP conversations over time, our findings underscore a need for physicians to receive education on how to appropriately document and bill for ACP conversations.

Structured documentation templates in the EMR have been suggested as a tool to increase the rate of documentation. ${ }^{21,22}$ Such templates can function as a checklist to remind clinicians about the necessary components of the clinical note to ensure that billing for ACP is successful. Qualified health care providers such as physicians, PAs, and ARNPs should also confirm with their billing staff that their fee schedule includes codes 99497 and 99498.

Analysis of 1 patient (ID \#17) led to an unexpected finding of a submitted charge where a physician properly documented the necessary components for 99497, but failed to be reimbursed. On further investigation of the case, it was discovered that 99497 had not been used in the department until September 2018, and reimbursement for 99497 and 99498 had not yet been added to the department's fee schedule.

The scope of this study was purposely restricted to assessing the use of ACP billing codes and the content of clinical documentation in the EMR. To assess the quality of the ACP conversations, they would need to be recorded, transcribed and qualitatively analyzed.

\section{Conclusion}

Since its introduction in January 2016, ACP code 99497 has rarely been used at this Midwestern tertiary care center in the United States. The add-on code 99498 was never used. Components of documentation that led to reimbursement of 99497 were that Medicare rules were followed, specifically that 1) ACP was conducted voluntarily; 2) the consent of the patient was obtained; 3) a qualified health care provider conducted the ACP discussion; and 4) a qualified health care provider spent greater than $50 \%$ of 30 minutes, that is, at least 16 minutes, face-to-face with the patient discussing ACP. The 2 most common reasons for failed reimbursement were when ACP was conducted by a nonqualified health care professional, even if they documented their discussion appropriately per Medicare rules, or a qualified health care professional did not document the minimum required face-to-face time.

The authors thank Mr. Jose Monestina, Senior Application Developer with UIHC Health Care Information Systems; Ms. Rozanne Murphy, CPC, Certified Medical Coder with UIHC Patient Financial Services/Coding Integrity Division; and Ms. Darcy Fortney, Revenue Cycle Manager with UIHC Patient Financial Services for providing assistance with data acquisition.

To see this article online, please go to: http://jabfm.org/content/ 32/6/827.full. 


\section{References}

1. Billings JA, Bernacki R. Strategic targeting of advance care planning interventions: the Goldilocks phenomenon. JAMA Intern Med 2014;174:620-624.

2. Brinkman-Stoppelenburg A, Rietjens JA, van der Heide A. The effects of advance care planning on end-of-life care: a systematic review. Palliat Med 2014;28:1000-1025.

3. Ackermann RJ. Care of Patients at the end of life: advance care planning. FP Essent 2016;447:25-31.

4. Balaban RB. A physician's guide to talking about end-of-life care. J Gen Intern Med 2000;15:195-200.

5. Dingfield LE, Kayser JB. Integrating advance care planning into practice. Chest 2017;151:1387-1393.

6. Wright MS. Change without change? Assessing Medicare reimbursement for advance care planning. Hastings Cent Rep 2018;48:8-9.

7. Jones CA, Acevedo J, Bull J, Kamal AH. Top 10 tips for using advance care planning codes in palliative medicine and beyond. J Palliat Med 2016;19:12491253.

8. Halpern SD, Emanuel EJ. Can the United States buy better advance care planning? Ann Intern Med 2015; 162:224-225.

9. Centers for Medicare \& Medicaid Services. CMS frequently asked questions about billing the physician fee schedule for advance care planning services. 2016. Available from: https:/www.cms.gov/Medicare/ Medicare-Fee-for-Service-Payment/PhysicianFeeSched/Downloads/FAQ-Advance-Care-Planning.pdf. Accessed February 5, 2019.

10. Zeltoun NK. The Hospitalist. New Medicare rule will reimburse physicians for advance care planning. 2015. Available from: https://www.the-hospitalist. org/hospitalist/article/122030/health-policy/newmedicare-rule-will-reimburse-physicians-advancecare.

11. Beck DE, Margolin DA. Physician coding and reimbursement. Ochsner J 2007;7:8-15.

12. Ariadne Labs. Serious illness conversation guide. 2017. Available from: https://www.ariadnelabs.org/
wp-content/uploads/sites/2/2018/04/Serious-Illness-Conversation-Guide.2017-04-18CC2pg.pdf. Accessed February 1, 2019.

13. Jensen PR. Coding "routine" office visits: 99213 or 99214? Fam Pract Manag 2005;12:52-57.

14. Hermansen CL, Jackson J. When is it right to code 99215? Fam Pract Manag 2014;21:12-16.

15. Young RA, Burge S, Kumar KA, Wilson J. The full scope of family physicians' work is not reflected by current procedural terminology codes. J Am Board Fam Med 2017;30:724-732.

16. Medicare program; revisions to payment policies under the physician fee schedule and other revisions to Part B for CY 2016. Final rule with comment period. Fed Regist 2015;80:70885-1386.

17. Cubanski J. Medicare Part D in 2018: the latest on enrollment, premiums, and cost sharing. Kaiser Family Foundation. 2019. Available from: https:// www.kff.org/medicare/issue-brief/medicare-part-din-2018-the-latest-on-enrollment-premiums-andcost-sharing/. Accessed January 18, 2019.

18. Grant M. Use of billing codes for advance care planning exceeds projections. August 10, 2017. Available from: https://www.thectac.org/2017/08/ use-billing-codes-advance-care-planning-exceedsprojections/. Accessed April 2, 2019.

19. Pelland K, Morphis B, Harris D, Gardner R. Assessment of first-year use of Medicare's advance care planning billing codes. JAMA Intern Med 2019;179: 827-829.

20. Belanger E, Loomer L, Teno JM, Mitchell SL, Adhikari D, Gozalo PL. Early utilization patterns of the new Medicare procedure codes for advance care planning. JAMA Intern Med 2019;179:829-830.

21. Huber MT, Highland JD, Krishnamoorthi VR, Tang JW. Utilizing the electronic health record to improve advance care planning: a systematic review. Am J Hosp Palliat Care 2018;35:532-541.

22. Saiki C, Ferrell B, Longo-Schoeberlein D, Chung V, Smith TJ. Goals-of-care discussions. J Community Support Oncol 2017;15(4):e190-e194. 